Proc. of the Eighth Intl. Conf. on Advances in Social Science, Management and Human Behaviour - SMHB 2019

Copyright (C) Institute of Research Engineers and Doctors. All rights reserved.

ISBN: 978-1-63248-168-9 DOI : 10.15224/978-1-63248-168-9-07

\title{
Implementing and managing processes that can encourage resilience in HIV and AIDS affected female teachers in township Early Childhood Development (ECD) centres
}

\begin{abstract}
:
Purpose

The purpose of this research project was to identify limitations in implementing and managing processes that can encourage resilience in HIV and AIDS affected female teachers in township Early Childhood Development (ECD) centres. Furthermore the aim was to identify guidelines to help these teachers to cope with their adversities in constructive ways.
\end{abstract}

\section{Design/methodologylapproach}

This research was grounded in a community-based participatory research approach. A qualitative research design was utilized because phenomena could be studied in terms of the meanings of people. Elements of grounded theory, situational analysis and community-based participatory research were blended. The qualitative research design involved open-ended questionnaires and semi-structured face-to-face interviews with teachers in township ECD centers.

\section{Findings}

The findings from this research revealed that HIV and AIDS affected all participants in a substantial way. The findings also made it evident that principals of ECD centres had not been trained to manage HIV and AIDS resilience of affected teachers in ECD centres. Teachers were not motivated and supported to get through their adversities in constructive ways.

The findings further revealed that three main processes encourage resilience in female teachers in township ECD centres, namely benefiting from constructive bonds, making meaning and acting constructively.

\section{Practical implications}

Challenges that could impede the effective implementation of an intervention programme should be identified and addressed. Principals of township ECD centres should be empowered to manage HIV and AIDS resilience in their centres effectively. A training programme aimed at empowering principals of ECD centres has been developed and will be implemented after consultation with the gatekeeper and principals of the ECD centres.

\section{Originality/value}

The findings of this research could be used by principals and researchers to reflect on management practices to support of HIV and AIDS affected female teachers in ECD centres. A challenge for principals is to acknowledge the principles of effective management and to close the gap between current practices and effective management practices. Interventions from academics are essential to enhance the quality of such an intervention programme. 